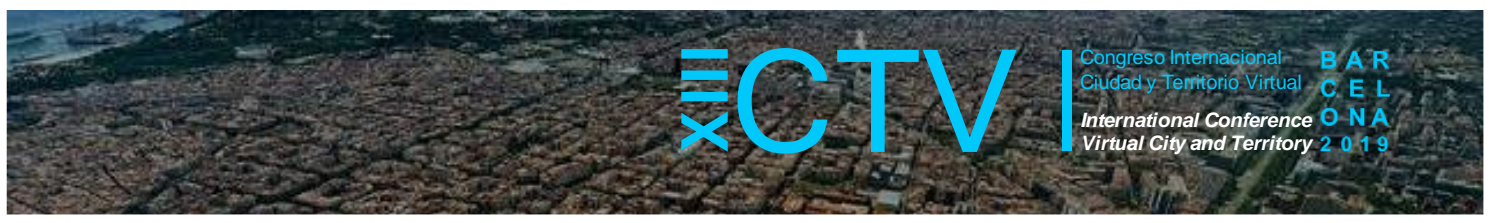

\title{
MATRIMONIO POR CONVENIENCIA: HOSPEDAJE COLABORATIVO Y VIVIENDA TURÍSTICA EN PUERTO VALLARTA, MÉXICO. UN ABORDAJE DESDE LA PLANEACIÓN URBANA
}

\author{
Baños Francia, José Alfonso 1; Huízar Sánchez, María de los Ángeles 2; López Ramos, Jorge \\ Luis $^{3}$
}

Remisión inicial: 2019-06-10; Remisión definitiva: 2019-10-20; Publicación: 2019-12-21

Citación: Baños, A. et al. (2019). Matrimonio por convivencia: Hospedaje Colaborativo y vivienda turística en Puerto Vallarta, México. Un abordaje desde la planeación urbana. En XIII CTV 2019 Proceedings: XIII International Conference on Virtual City and Territory: "Challenges and paradigms of the contemporary city”: UPC, Barcelona, October 2-4, 2019. Barcelona: CPSV, 2019, p. 8522. E-ISSN 2604-6512. DOI http://dx.doi.org/10.5821/ctv.8522

\section{Resumen}

En la participación se discute la relación entre el hospedaje colaborativo y la habilitación de vivienda turística en Puerto Vallarta, México, tomando como eje de análisis a la planeación urbana y sus instrumentos.

El desarrollo tecnológico experimentado a escala planetaria ha provocado profundos cambios en la producción y el consumo; así, surgen empresas que operan como intermediarios entre productores y consumidores, recurriendo a plataformas digitales en sectores como la movilidad, el transporte aéreo o el alojamiento. En estas prácticas, se recurre a plataformas innovadoras que forman parte de la llamada economía colaborativa.

En el hospedaje, se facilita la disponibilidad de viviendas particulares para cubrir este segmento de la oferta turística. La rapidez y calado en estas nuevas modalidades de alojamiento está ejerciendo una fuerte presión en los destinos turísticos a nivel mundial sin presentarse mecanismos de regulación o compensación eficaces.

Para analizar la huella del hospedaje colaborativo, la lente se enfoca en Puerto Vallarta, destino recreativo localizado en el océano Pacífico de México, tomando a los instrumentos de planeación urbana para el análisis. Vale comentar que el proceso de urbanización de las ciudades mexicanas (y en particular, las turísticas de litoral) se caracteriza por la aplicación incompleta del vasto instrumental urbanístico de que dispone, debido a la debilidad del entramado institucional, donde terminan imponiéndose intereses particulares que resultan en prácticas extractivas en detrimento de los bienes comunes.

De esta manera, los planes urbanísticos en zonas con alto dinamismo inmobiliario no se actualizan ni atienden las tensiones generadas por la expansión. Operacionalmente, se recurre a modificar en forma discrecional las normas de control urbanísticas con el objetivo de incrementar la oferta en el mercado inmobiliario.

Ello supone la existencia de acuerdos informales entre promotores inmobiliarios, gremios de constructores y funcionarios gubernamentales (sobre todo a nivel municipal) para facilitar la alteración en las reglas del juego y acrecentar la rentabilidad de los nuevos emprendimientos.

En este trabajo, se examinó la oferta de hospedaje colaborativo entre 2010 y 2018, documentando la expansión en la vivienda turística en dos barrios representativos de la localidad: Zona Romántica y Marina Vallarta. Para indagar los instrumentos de planeación urbana se recurrió a documentos oficiales que fueron contrastados con datos empíricos en los barrios analizados.

Entre las conclusiones, se apunta que: 1) la disponibilidad de plataformas digitales a nivel mundial incide en la emergencia de nuevas formas de hospedaje, teniendo en México y en Puerto Vallarta un campo dinámico y atractivo; 2) la actividad recreativa impulsa el auge de viviendas turísticas, sobre todo en barrios atractivos; 3 ) los planes urbanísticos son modificados discrecionalmente para maximizar la oferta inmobiliaria, poniendo en entredicho la

1 Doctor en Ciudad y Territorio, Universidad de Guadalajara. Email: jose.banos@academicos.udg.mx; cyberponx@yahoo.com. Orcid: https://orcid.org/0000-0003-4734-9368; ${ }^{2}$ Doctora en Ciudad y Territorio, Universidad de Guadalajara. Email: angelesleo@hotmail.com. Orcid: https://orcid.org/0000-0002-8051-4241; ${ }^{3}$ Doctor en Ciencias para el Desarrollo Sustentable, Universidad de Guadalajara. Correo de contacto: prescipción@hotmail.com 


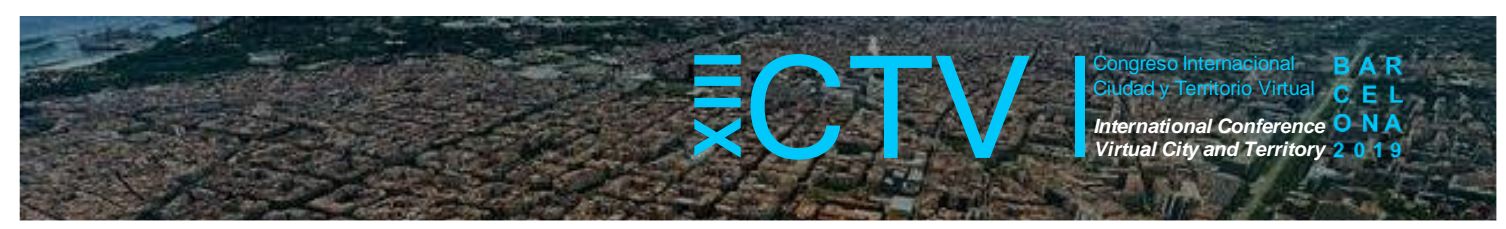

institucionalidad del ordenamiento territorial; 4) el Estado, en particular el gobierno municipal deja de ser el ente regulador entre los derechos de propiedad y desarrollo urbanístico para conceder atribuciones inmoderadas al sector privado en Puerto Vallarta; $y, 5$ ) es pertinente impulsar mecanismos para gestionar las tensiones generadas por el hospedaje colaborativo y la vivienda turística, bajo una perspectiva de prosperidad comunitaria.

\section{Abstract}

The paper discusses the relationship between collaborative lodging and the provision of tourist housing in Puerto Vallarta, Mexico, taking urban planning and its instruments as the axis of analysis.

The technological development experienced on a global scale has brought deep changes in production and consumption. Thus, companies emerge that operate as intermediaries between producers and consumers, resorting to digital platforms in sectors such as mobility, air transport or accommodation. In these practices, innovative platforms that are part of the so-called collaborative economy are used.

In accommodation, the availability of private homes facilitates to cover this segment of the tourist offer. The speed and depth of these new forms of accommodation are putting strong pressure on tourist destinations worldwide without effective regulatory or compensation mechanisms.

To analyze the footprint of collaborative lodging, the lens focuses on Puerto Vallarta, a recreational destination located in the Pacific Ocean of Mexico, taking the urban planning instruments for the analysis. The urbanization process of Mexican cities (and in particular, tourist on the coast) is characterized by the incomplete application of the vast urban planning tools available to it, due to the weakness of the institutional framework, where private interests end up imposing themselves, resulting in extractive practices to the detriment of common good.

Therefore, urban plans in areas with boom in real estate maintains with proper updated or ways to address the tensions generated by the expansion. Operationally, modifying urban planning control rules in a discretionary manner it is a common practice with the aim of increasing the offer in the real estate market.

This implies the existence of informal agreements between real estate developers, builders and government officials (especially at the municipal level) to facilitate the alteration in the rules to increase the profitability of new ventures.

In the work, was reviewed the offer of collaborative lodging between 2010 and 2018, documenting the expansion in tourist housing in two representative neighborhoods of the town. Urban planning instruments and official documents compared with empirical data in the analyzed zones.

Among the conclusions, it is pointed out that: 1) the availability of digital platforms worldwide affects the emergence of new forms of accommodation, having a dynamic and attractive field in Mexico and Puerto Vallarta; 2) recreational activity drives the boom in tourist homes, especially in attractive neighborhoods; 3) urban plans are modified discretionary to maximize the real estate offer, calling into question the functionality of the territorial management; 4) the State, in particular the municipal government, ceases to be the regulatory entity between property rights and urban development to grant immoderate powers to the private sector in Puerto Vallarta; 5) it is pertinent to promote mechanisms to manage the tensions generated by collaborative lodging and tourist housing, under a perspective of community prosperity.

Palabras Clave: vivienda turística; hospedaje colaborativo; planeación urbana; Puerto Vallarta

Keywords: tourist housing; collaborative lodging; urban planning; Puerto Vallarta

\section{Introducción}

Puerto Vallarta se localiza en la costa del Pacífico mexicano; integra el segundo asentamiento con mayor población en el estado (provincia) de Jalisco, detrás del Área Metropolitana de Guadalajara (AMG). La principal vocación es la actividad turística en la modalidad de sol y playa, recibiendo más de cinco millones de visitantes en 2019 (Pineda, 2020). 


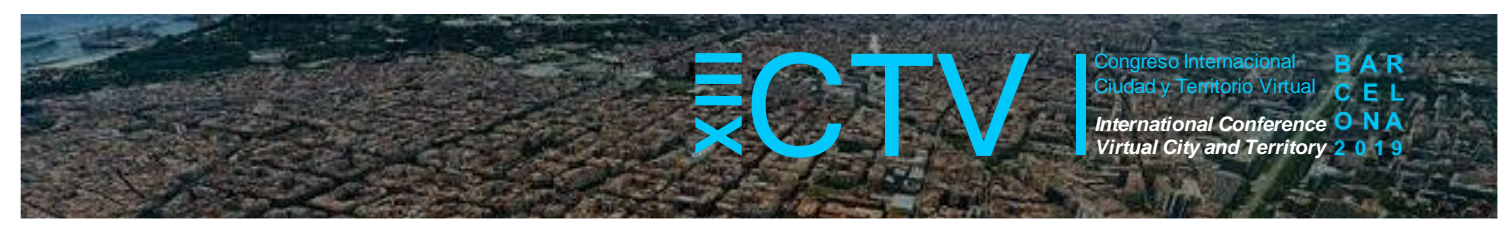

El destino ha alcanzado un estado de madurez en el ciclo de vida turístico y enfrenta tensiones en varias dimensiones (Huízar, 2018), las cuales alcanzan al hospedaje, la vivienda turística y la planeación urbana (Baños, 2018).

Para abordar esta dinámica, la investigación se despliega en cinco etapas. La primera, para acercarse a los principios de la economía colaborativa recurriendo a los postulados teóricos de la temática. La segunda, orientada a identificar los elementos del hospedaje colaborativo, adoptando técnicas documentales y empíricas. En la tercera, se describen los componentes de la vivienda turística, enfocando la mirada en dos barrios emblemáticos en la localidad. La cuarta parte analiza los instrumentos de planeación urbana aplicados en el municipio vallartense, cuyas bases descansan en el paradigma racional. Finalmente, se esbozan consideraciones para la gestión del hospedaje colaborativo, asociado a los instrumentos de planeación turística en Puerto Vallarta y que pudieran ser replicados en otros destinos de playa en México.

El trabajo se hilvanó con dos supuestos. El primero, que las transformaciones globales asociadas al uso de tecnologías de información y comunicación (TIC's) alientan nuevas formas de intercambio de bienes y productos etiquetadas como colaborativas. $Y$ una de las más populares incide en el hospedaje, influyendo en un auge en la edificación de viviendas turísticas en destinos recreativos como el presentado.

El segundo, aventura que la práctica de planeación urbana no dispone de mecanismos para responder a los acelerados procesos de tecnificación del hospedaje colaborativo, cuya impronta territorial está generando tensiones sociales, ambientales y económicas en la comunidad receptora.

Por ello, es prioritario formular instrumentos de gestión que permitan conciliar los intereses asociados al hospedaje colaborativo y la vivienda turística. De lograrse, podrían potenciarse las oportunidades y reducir las tensiones en comunidades cuya principal actividad es el turismo.

\section{Acercamiento a la economía colaborativa}

El intercambio de bienes y servicios es un elemento fundamental para las sociedades, desde los albores hasta la actualidad. Las transacciones comerciales más antiguas ocurrían mediante trueque, antes de adoptar a la moneda como forma habitual de pago (Harari, 2014).

Los cambios aparejados a la modernidad y al desarrollo de las tecnologías de la información y comunicación (TIC's) alentaron que el intercambio entrara al plano digital aprovechando las facilidades de conexión que brinda el internet.

Hace algunos años, Rifkin identificaba los cambios introducidos por los medios tecnológicos, puntualizando que los mercados aprovechan los canales de conexión mediante redes digitales, surgiendo nuevas prácticas de consumo donde vendedores y compradores se transforman en proveedores y usuarios a la vez. Así, se pasa del régimen de propiedad (tangible) a otro caracterizado por el acceso y con ello, garantizar el uso limitado y a corto plazo de los bienes controlados por redes de proveedores (2000:5). 


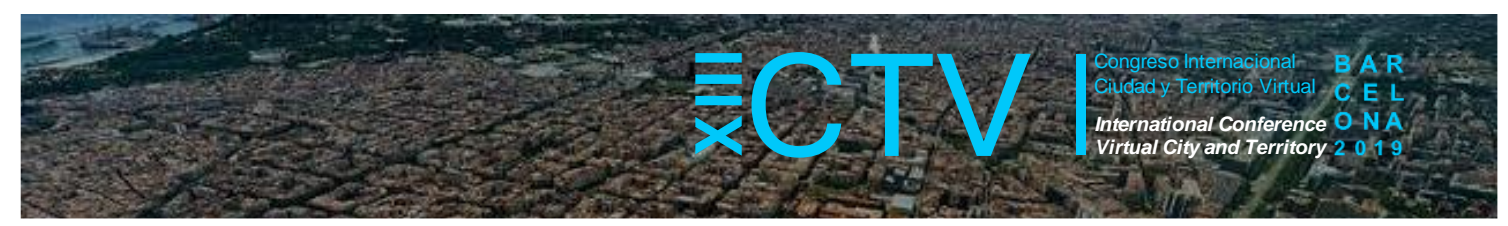

Los avances tecnológicos, la expansión del internet y las redes sociales consolidaron el modelo del acceso, acelerando el intercambio de bienes y servicios entre particulares y empresas y dando paso a nuevas expresiones económicas etiquetadas como colaborativas. Muchas voces aventuran que este modelo opera como una alternativa al paradigma del consumo capitalista, aparentemente ilimitado.

Botsman y Rogers (2010), presentan un panorama halagador sobre el desarrollo de la economía colaborativa, al presentarla como un movimiento social, donde resaltan las ventajas del intercambio entre individuos (peer to peer) para reducir el consumo desmedido de la sociedad moderna. Bajo este mismo enfoque, se aborda el hiper-consumo y las ventajas de la economía y sociedad colaborativa, donde los conceptos compartir, colaborar, reutilizar y reciclar son esenciales ante la imperante y urgente necesidad de reorientar la economía para ponerla al servicio y a la escala de las personas. Una sociedad con las personas en el centro (Cañigueral, 2014:12).

Para el autor, el consumo colaborativo propone compartir los bienes frente a poseerlos, $y$ focalizarse en poner en circulación todo aquello que ya existe (Ibíd: 16), haciendo énfasis en las ventajas del acceso sobre la posesión; también apunta que esta actividad con la adición del internet y las redes sociales adquiere una escala, dimensión y velocidad de amplio espectro.

De acuerdo con Alonso y Miranda (2017) la economía colaborativa constituye un nuevo paradigma económico y social, recurriendo a la tecnología como instrumento para desafiar las contradicciones del capitalismo clásico. Aunque estos autores advierten que es prematuro anunciar el fin del modelo actual, intuyen que la sociedad se encuentra en una etapa de transición, donde será necesario identificar los roles que asumirán el mercado, el Estado y la sociedad, previendo que, "el crecimiento y el auge de este tipo de iniciativas colaborativas demuestra un deseo generalizado para encontrar soluciones basadas en la colaboración... y el surgimiento de nuevas actitudes sociales, cada vez más generosas, más solidarias y menos jerárquicas" (21-22).

Un atributo en este modelo económico es la flexibilidad que tienen los particulares para disponer de un ingreso añadido y empleo complementario mediante la colocación en el mercado de productos o servicios subutilizados. Así mismo, la demanda se ve favorecida por el incremento de bienes o actividades a los que se puede acceder. El paradigma de la economía colaborativa se asume como imparable, revolucionario y disruptivo, cuya presencia pueda contrarrestar los efectos perniciosos del capitalismo tradicional.

\section{El hospedaje colaborativo}

Bajo el paradigma de la economía colaborativa, han surgido empresas que operan como intermediarios entre productores y consumidores utilizando plataformas digitales, entre las que destacan Uber y Airbnb, posicionadas como íconos dentro de este modelo, la primera en el sector de la movilidad y la segunda en el hospedaje. A ésta última, se le reconoce como una empresa innovadora y disruptiva que ofrece experiencias que contrastan con el servicio estandarizado del hotelería tradicional.

Airbnb, formada en 2008, ha captado la atención debido a su acelerado crecimiento, colocándose entre las empresas mejor valuadas por los mercados financieros, logrado un 


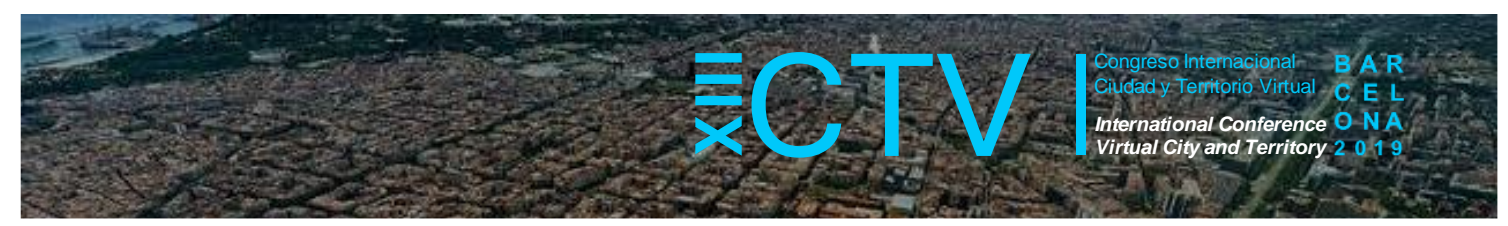

proceso de expansión mundial, al ofertar bajo una misma plataforma miles de viviendas particulares para hospedaje, sobre todo en destinos turísticos populares y grandes ciudades. La elevada demanda mundial de alojamiento temporal ha encontrado un nicho interesante, en esta modalidad, antes controlado por las compañías hoteleras. Al entrar al mercado un alto volumen de unidades en un periodo corto, se acelera la oferta de hospedaje colaborativo o alternativo, ejerciendo una presión añadida para los destinos turísticos.

La impronta en la ciudad sugiere que el hospedaje colaborativo se acerca más a una nueva forma de acumulación para la empresa intermediaria y una gran oportunidad de negocio para los desarrolladores y administradores inmobiliarios, quienes se están apropiando de las zonas de alto valor turístico, saturando con edificaciones de gran altura, en espacios reducidos e impulsando dinámicas inéditas de gentrificación, segregación y exclusión (Brossat, 2018). El calado en las transformaciones del hospedaje colaborativo ha tomado por sorpresa a las autoridades locales, las cuales parecen, en el mejor de los casos, más interesadas en aplicar tasas impositivas que en generar mecanismos de gestión integrales. Da la impresión que, desde la administración pública, no se alcanza a visualizar los impactos y prestan oídos sordos a quienes cuestionan el comportamiento de esta modalidad de hospedaje.

La operación de Airbnb y empresas similares ha generado tensiones en la esfera social, económica, legal y territorial en muchas ciudades; en sitios icónicos como Nueva York, Barcelona, París y Ámsterdam, la comunidad denuncia las problemáticas relacionadas, como la competencia desleal para las empresas de hospedaje formal, el incremento del alquiler y la constante gentrificación. A ello se suman los conflictos derivados de la inserción del turista en los espacios de vida cotidiana de los residentes, requiriéndose encontrar fórmulas para atender esta dinámica. Ante la emergencia de estas tensiones, Slee señala que la economía colaborativa está introduciendo un libre mercado despiadado y desregulado en ámbitos de nuestras vidas anteriormente protegidos (2017:15). Así mismo, establece que las empresas que pregonan los beneficios de la economía colaborativa para sus usuarios se han convertido en monstruos corporativos y están desempeñando un papel cada vez más intrusivo en las transacciones que fomentan para ganar dinero y mantener su marca (Ibíd:15-16).

Bajo este esquema, la meta es capitalizar los activos de terceros para obtener un beneficio financiero, pero sin asumir riesgos, ni compromisos laborales o sociales, enfocando el enriquecimiento de la empresa que provee el servicio. Tampoco se asumen responsabilidades por las fracturas que generan en el tejido socioeconómico de las comunidades en que se insertan, en una forma de maximización de la rentabilidad, misma que Brossat (2018) define como capitalismo hardcore.

\section{El hospedaje colaborativo en México y Puerto Vallarta}

En México, el arrendamiento o préstamo de viviendas turísticas es una práctica común en los principales destinos, que llevan a cabo, tanto nacionales como extranjeros (Hiernaux, 2007). Sin embargo, con la expansión del internet y la creación de plataformas digitales exprofeso, la actividad se ha incrementado considerablemente. La instalación de oficinas corporativas de Airbnb en el país, dan cuenta de la importancia que ha cobrado este destino en el hospedaje colaborativo en Latinoamérica, posicionándose en el segundo sitio con 37 mil propiedades, superado únicamente por Brasil (a21mx, 2017). 


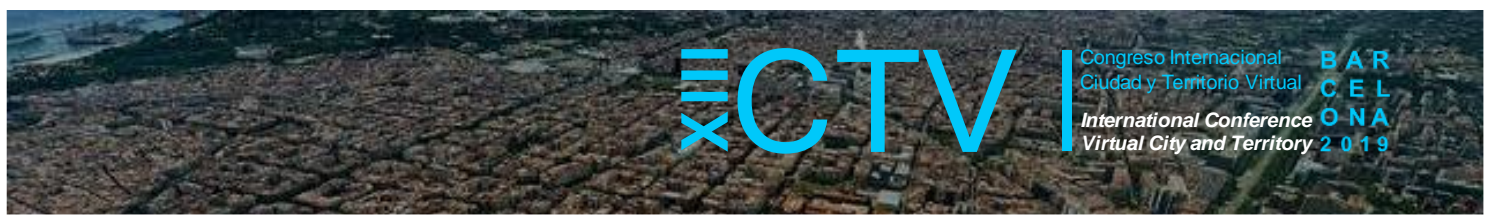

Según datos del Instituto Mexicano para la Competitividad (IMCO, 2017) Playa del Carmen, Ciudad de México y Puerto Vallarta, figuran entre los diez principales destinos de Airbnb en Latinoamérica. En Puerto Vallarta, Airbnb inició operaciones en el año 2010 presentando una tasa de crecimiento superior al $60 \%$ anual (Airdna, 2018), cifra que da cuenta del interés que ha despertado esta modalidad de hospedaje e impactando al sector turístico local en dos sentidos: el primero, registrando un incremento del número de anfitriones que agregan la mayor cantidad de propiedades con la meta de incrementar sus ingresos; y el segundo, estimulando la inversión inmobiliaria. Ello supone incrementar la oferta mediante la edificación de emprendimientos con el mayor número de unidades posible, reduciendo la superficie de cada unidad e incrementando la altura. Pero la piedra clave en este esquema está en la modificación discrecional de las normas de control contenidas en los planes urbanísticos.

La consolidación de Puerto Vallarta como destino turístico contó con el apoyo de los tres niveles de gobierno (federal, estatal y municipal), dotando de la infraestructura necesaria para el establecimiento de la planta turística en la segunda mitad del siglo XX. Uno de los pilares de la oferta turística se basó en la consolidación del sector hotelero, que se mantuvo en constante expansión, proceso acompañado a menor ritmo por la modalidad extra-hotelera (mayoritariamente departamental) como se muestra en la tabla 1.

Tabla 1. Oferta hotelera y extra-hotelera en Puerto Vallarta (1975-2015)

\begin{tabular}{cccc}
\hline Año & Habitaciones hoteleras & Habitaciones extra-hoteleras & Total \\
\hline 1975 & 2,687 & Sin datos & No aplica \\
\hline 1980 & 4,590 & Sin datos & No aplica \\
\hline 1985 & 6,517 & 3,386 & 9,903 \\
\hline 1990 & 8,805 & 5,295 & 14,100 \\
\hline 1995 & 8,957 & 6,262 & 15,219 \\
\hline 2000 & 9,896 & 7,781 & 17,677 \\
\hline 2005 & 11,119 & 7,717 & 18,836 \\
\hline 2010 & 10,413 & 10,793 & 21,206 \\
\hline 2015 & 13,267 & 12,120 & 25,387 \\
\hline
\end{tabular}

Fuente: Secretaría de Turismo de Jalisco (2015, 2010, 2005); Gómez Encarnación (2008); César y Arnaiz (2006).

Mapa 1. Localización de Puerto Vallarta

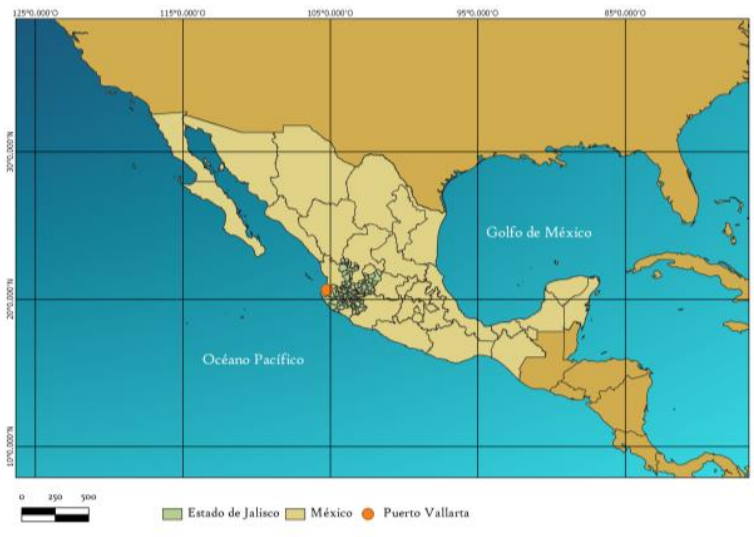

Fuente: elaboración propia con QGis.

En la década de 1980 aparece el tiempo compartido, modalidad que generó controversia por la competencia que significaba para la práctica hotelera por el reducido número de empleos creados (López, 2020; RCl, 2017). Adicionalmente, creció la oferta de hospedaje extra-hotelero a partir de la entrada del siglo XXI, debido al auge inmobiliario global que terminó por 


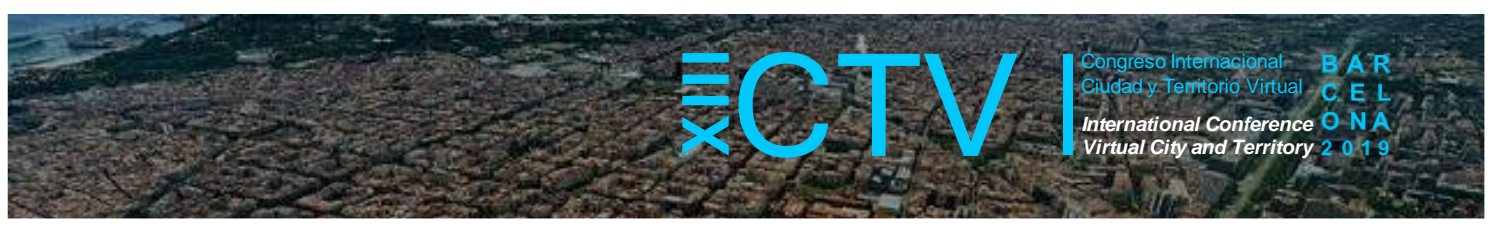

desinflarse con la crisis hipotecaria global del 2007 (Baños, 2017; Soros, 2008). Para el año 2015, la oferta combinada de hospedaje es de 25,387 (SECTURJAL, 2015), distribuida a lo largo de la franja turística².

En 2017, Puerto Vallarta contaba con 4,400 propiedades registradas en Airbnb, bajo el esquema del hospedaje colaborativo (IMCO). Un año después, los datos de Airdna (2018) muestran que la oferta se incrementó a 5,268 propiedades, con una tasa de crecimiento anual del $63 \%$ y una tarifa promedio diaria de dos mil doscientos pesos 3 ; cabe recordar que los precios se ajustan a la temporalidad y tipo de unidad, de manera que se puede compartir una habitación fuera de la zona turística por ciento veinte pesos la noche ${ }^{4}$, o alquilar una lujosa villa en las colonias más exclusivas del municipio por casi sesenta mil pesos por jornada ${ }^{5}$.

De las propiedades que integran la oferta de hospedaje colaborativo, el $84 \%$ corresponde a casas y departamentos completos, aspecto que no coincide con el objetivo de compartir y mucho menos, experimentar la inmersión en la localidad como sugiere el legado de Airbnb. En cuanto a la distribución territorial, la oferta de hospedaje colaborativo mantiene un patrón similar al modelo hotelero, concentrándose a lo largo de la línea de playa, sin embargo, debido a la naturaleza flexible del modelo de negocio de Airbnb, la oferta no se limita a la franja turística y muestra una expansión sostenida hacia las colonias aledañas o marginales, cuya localización puede distar varios kilómetros del litoral. Hay dos barrios turísticos emblemáticos que destacan: la Zona Romántica y Marina Vallarta; ambos cuentan con un fuerte interés recreativo, registrándose una amplia oferta de hospedaje colaborativo. Pero también experimentan un crecimiento inmobiliario significativo, impulsando una serie de conflictos vecinales, que, de acuerdo con la hipótesis del presente trabajo, obedecen al auge reciente del hospedaje colaborativo.

\subsection{La Zona Romántica}

La Zona Romántica es un barrio icónico en Puerto Vallarta que se distingue por ser una centralidad relevante de la comunidad LGBT, la cual cuenta con una amplia oferta de servicios dirigidos a este segmento caracterizado por disponer de un elevado poder adquisitivo (Huízar, Baños y López, 2018). Anexo al barrio se encuentra el centro histórico, espacio fundacional que configuró una fisonomía de poblado tradicional mexicano, expresada con fincas de poca altura, calles estrechas, muros pintados de color blanco y techumbres cubiertas con cerámica roja. Dicho atributo fue una ventaja competitiva de Puerto Vallarta ante otros destinos turísticos de playa en México, aspecto que se ha ido diluyendo ${ }^{6}$.

\footnotetext{
${ }^{2}$ La franja o zona turística de Puerto Vallarta alberga la oferta recreativa, desarrollándose de manera lineal al litoral, en una extensión aproximada de 25 kilómetros y una superficie cercana a las 1,100 hectáreas. La estructuración privilegia el uso privado en detrimento del aprovechamiento público, observándose dos componentes: el primero contenido a borde de playa, con predios anexos y visuales atractivas; y el segundo, la zona de montaña en donde se aprovechan las cualidades paisajísticas.

${ }^{3}$ Equivalentes a unos ciento diez dólares de Estados Unidos de América, de acuerdo al tipo de cambio promedio del segundo semestre del 2019.

${ }^{4}$ Equivalentes a unos seis dólares de Estados Unidos de América, de acuerdo al tipo de cambio promedio del segundo semestre del 2019.

${ }^{5}$ Equivalentes a unos tres mil dólares de Estados Unidos de América, de acuerdo al tipo de cambio promedio del segundo semestre del 2019.

${ }^{6}$ El valor del patrimonio arquitectónico de la Zona Romántica quedó consignado al ser declarado dentro del Perímetro de Protección a la Imagen Urbana y Conservación del Patrimonio Cultural dentro del Programa para la Conservación del Patrimonio Cultural del Estado de Jalisco (2014), página 67 de la Dirección de Patrimonio Artístico e Histórico de la Secretaría de Cultura de Jalisco.
} 


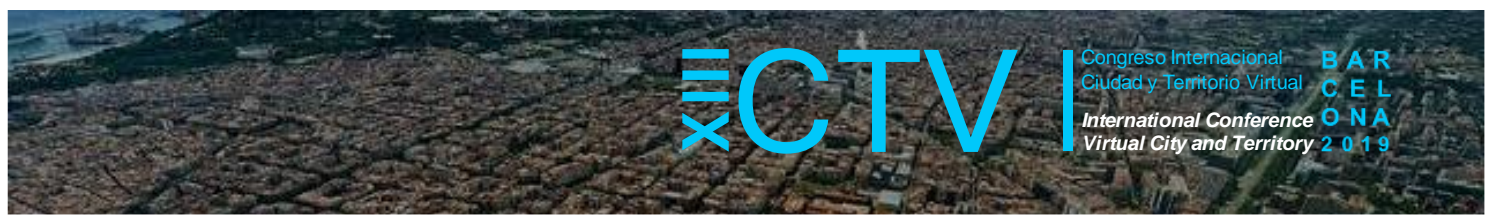

A partir del año 2010, sobrevino un intenso proceso de urbanización con la edificación de numerosos desarrollos inmobiliarios que incrementaron la oferta en más de seiscientas unidades habitacionales; actualmente, se han autorizado diez emprendimientos más, los cuales se encuentran en etapa de construcción. Como se observa en la tabla 2, los nuevos emprendimientos se distribuyen en una superficie superior a una hectárea, pero con una masa edificada ocho veces mayor; es decir, ocurre una intensa densificación en relación con los predios anexos. Destaca que se construyeron 675 unidades privativas (departamentos), cifra que rebasa las 128 unidades posibles de acuerdo al instrumento urbanístico vigente ${ }^{7}$, edificándose 547 unidades adicionales a lo establecido por la normatividad.

Tabla 2. Desarrollos inmobiliarios recientes en la Zona Romántica

\begin{tabular}{|c|c|c|c|c|c|c|c|}
\hline Desarrollo & $\begin{array}{l}\text { Superficie } \\
\text { terreno } \mathrm{m}^{2}\end{array}$ & $\begin{array}{c}\text { Superficie } \\
{\text { construible } \mathbf{m}^{2}}^{\text {normativa }^{\star}}\end{array}$ & $\begin{array}{l}\text { Superficie } \\
\text { construida }\end{array}$ & $\begin{array}{l}\text { Unidades } \\
\text { privativas }\end{array}$ & $\begin{array}{c}\text { Unidades } \\
\text { privativas } \\
\text { normativa* }\end{array}$ & $\begin{array}{c}\text { Altura } \\
\text { (niveles) }\end{array}$ & $\begin{array}{c}\text { Altura } \\
\text { normativa } \\
\text { (niveles)* }\end{array}$ \\
\hline Pacífica & 641.00 & $1,346.10$ & $3,846.00$ & 36 & 5 & 7 & 3 \\
\hline The Park & $1,240.30$ & $2,604.63$ & $7,982.10$ & 54 & 10 & 7 & 3 \\
\hline Zenith & 938.50 & $1,970.85$ & $9,672.00$ & 46 & 8 & 7 & 3 \\
\hline V399 & 728.00 & 728.00 & & 55 & 11 & 7 & 3 \\
\hline $\begin{array}{c}\text { Rincón de } \\
\text { Almas }\end{array}$ & 798.70 & $1,677.27$ & $3,511.20$ & 38 & 7 & 7 & 3 \\
\hline Pier 57 & $1,248.00$ & $2,620.80$ & $9,821.00$ & 69 & 10 & 7 & 3 \\
\hline Oceana & 665.80 & $1,398.18$ & $5,205.85$ & 30 & 6 & 7 & 3 \\
\hline Nayri & $1,068.10$ & $2,243.01$ & $6,939.72$ & 54 & 9 & 7 & 3 \\
\hline Loft 268 & $1,232.90$ & $2,589.09$ & $9,440.99$ & 64 & 10 & 7 & 3 \\
\hline Pavillion & $1,240.66$ & $2,605.39$ & $8,209.59$ & 61 & 10 & 7 & 3 \\
\hline Urban & 300.00 & 630.00 & $2,094.00$ & 12 & 3 & 7 & 3 \\
\hline Pinnacle 1 & $1,075.90$ & $1,291.08$ & $8,607.20$ & 48 & 4 & 7 & 3 \\
\hline Pinnacle 2 & 948.28 & $1,137.94$ & $7,586.24$ & 57 & 8 & 7 & 3 \\
\hline $105^{\circ}$ Sail View & $1,279.50$ & $1,535.10$ & $6,722.075$ & 53 & 25 & 10 & 3 \\
\hline Total & $14,024.99$ & $26,479.39$ & $94,734.64$ & 675 & 128 & No aplica & No aplica \\
\hline
\end{tabular}

* Considerando el Plan Parcial de Plan Parcial de Desarrollo Urbano Los Muertos aprobado vigente.

Fuente: elaboración propia basada en investigación empírica e información oficial proporcionada por la Dirección de Desarrollo Urbano y Ecología del Ayuntamiento de Puerto Vallarta.

La plusvalía de estos emprendimientos no fue capturada en porcentaje alguno para beneficio de la hacienda pública, dejándose pasar la oportunidad de financiar la rehabilitación de infraestructura, movilidad o espacio público requerido. Para remediar esta situación, el Ayuntamiento vallartense generó un mecanismo denominado ICUS (Incremento al Coeficiente de Ocupación del Suelo) hasta el año $2019^{8}$, cuando la urbanización ya había generado impactos a la servicios básicos existentes.

Para materializar la intensa urbanización, los promotores inmobiliarios recurrieron (en todos los casos analizados) a formular y presentar un mecanismo denominado Análisis Técnico Justificativo (ATJ) ${ }^{9}$, mediante el cual los promotores de un desarrollo, objetan lo establecido en el instrumento de planeación urbana (en este caso, un Plan Parcial) y solicitan al Ayuntamiento que las normas de control urbanísticos se modifiquen a voluntad de los promotores. Este mecanismo, altamente discrecional ha sido descalificado por las autoridades judiciales de

\footnotetext{
${ }^{7}$ Correspondiendo al Plan Parcial de Desarrollo Urbano Los Muertos, aprobado por el Ayuntamiento de Puerto Vallarta en el año 2000 y aún vigente.

${ }^{8}$ De acuerdo a la Ley de Ingresos 2018 del Ayuntamiento de Puerto Vallarta, la captura de plusvalía se estableció en \$ 1,800 pesos por metro cuadrado, equivalente a $\$ 90$ dólares estadounidenses (al tipo de cambio de diciembre de 2019). En caso de haberse aplicado el ICUS con antelación en la Zona Romántica, se pudo haber ingresado 5.72 millones de dólares estadounidenses.

${ }^{9}$ Para sostener este supuesto, se obtuvieron los expedientes de los catorce desarrollos en cuestión y en cada uno de ellos, el procedimiento de modificación fue la presentación de un Análisis Técnico Justificativo (ATJ), avalado por un profesional de la construcción, así como por la autoridad municipal en turno.
} 


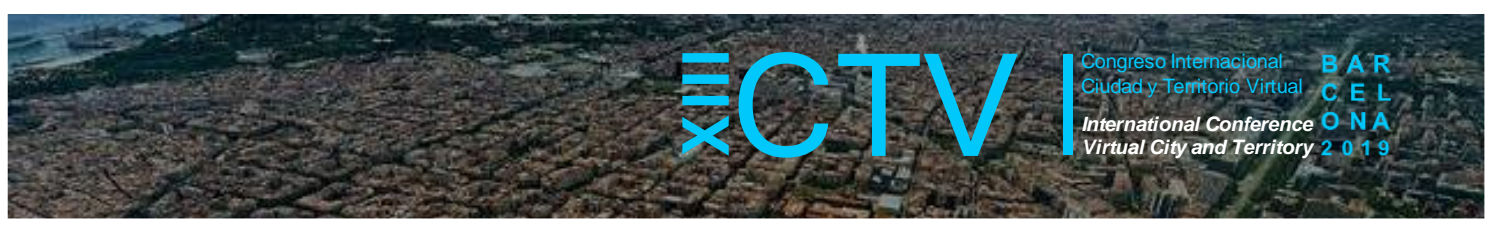

Jalisco, subrayando la inaplicabilidad de tal medida ${ }^{10}$. El alcance en la gestión de los servicios públicos muestra ya sus efectos. Así, de acuerdo con el director del organismo operador del agua y alcantarillado a nivel local, la línea de drenaje (que tiene una vida útil de 40 años) amenaza con colapsar, requiriéndose una inversión de 150 millones de pesos ${ }^{11}$ para adecuarlo (Mora, 2017). Ello ya tuvo implicaciones al romperse la principal línea de conducción del alcantarillado en marzo del 2019. A pesar de la gravedad de estas alarmas, no aparecen en el horizonte mecanismos para atenderlos.

Figura 2. Vista de la Zona Romántica en Puerto Vallarta

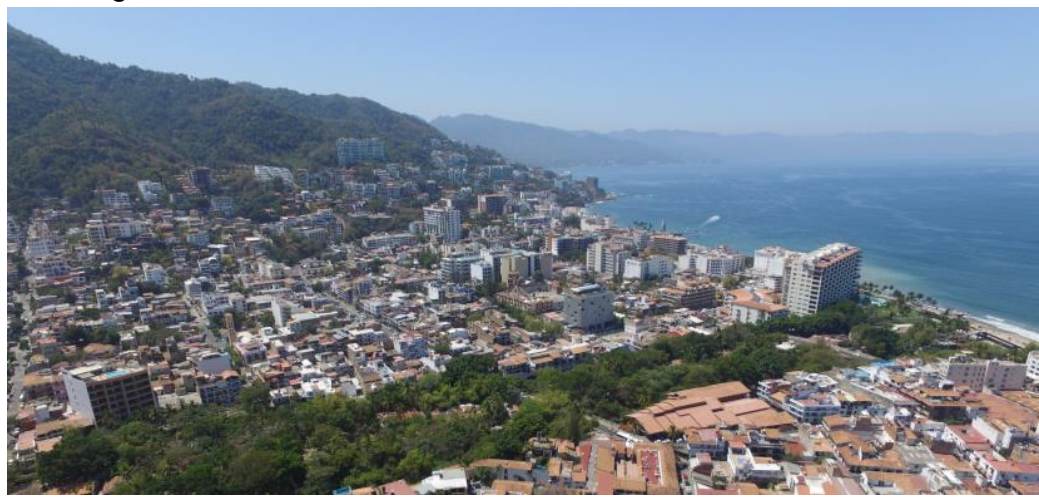

Fuente: autores

El incremento en la demanda y las adecuaciones en la oferta de los nuev0s edificios impactan en el precio del suelo que va al alza; de acuerdo al presidente de la Asociación de Comercios Turísticos LGBT, la Zona Romántica tiene el metro cuadrado más caro de toda la ciudad (García, 2019). Dicha situación genera una presión añadida sobre viviendas, comercios, espacios públicos y equipamientos (como escuelas $u$ hospitales) robusteciendo el desplazamiento de la población local (gentrificación), escenario que impulsa tensiones y protestas de los vecinos, quienes alertan sobre la disminución en las condiciones de habitabilidad (ruido excesivo, carencia de estacionamientos y criminalidad) al tiempo que se resisten a mudarse. Al respecto, en el diario Vallarta Opina aparece que, "La voracidad de quien construye y paga la obra va de la mano con la autoridad que ha permitido la creación de estos edificios que ya denotan saturación a la vista, ofertando condominios de lujo para unos cuantos que modificarán el entorno de una comunidad que no ha sabido defender su identidad" (Ocaña, 2017).

\subsection{Marina Vallarta}

El conjunto de Marina Vallarta fue urbanizado a partir de 1985, incorporando una mezcla de usos con vocación turística con predios para hoteles frente al mar, departamentos en torno a una marina y campo de golf, vivienda unifamiliar, así como nodos de servicios, negocios y comercios enfocados a un segmento de población de altos ingresos. De los atractivos resalta un paseo marítimo (malecón) que agrupa restaurantes y sitios lúdicos, consolidándose como uno los sitios más deseados en Puerto Vallarta por sus buenas condiciones de habitabilidad.

\footnotetext{
${ }^{10}$ Como se establece en la demanda de amparo 863/2018 en el Juzgado Segundo en Materia Administrativa, Civil y de Trabajo en el Estado de Jalisco.

${ }^{11}$ Equivalentes a unos siete y medio millones de dólares de Estados Unidos de América, de acuerdo al tipo de cambio del segundo semestre del 2019.
} 


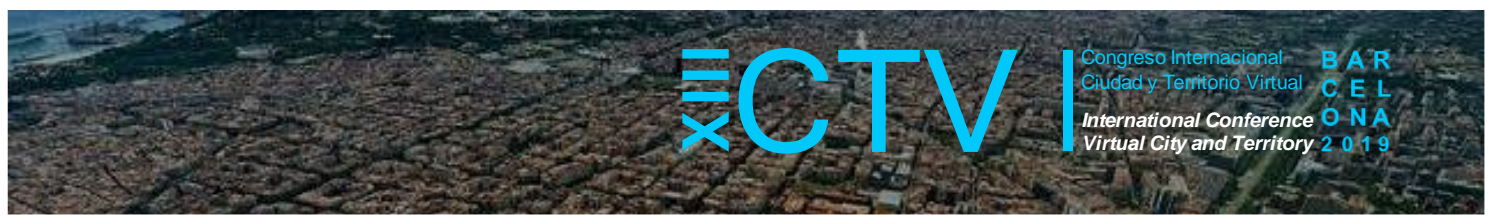

Así, la oferta inmobiliaria es activa, recurriendo a la alteración de los instrumentos de planeación urbana para incrementar rentabilidad de las inversiones ${ }^{12}$.

La habilitación de la vivienda turística en la zona se puede clasificar en 3 periodos. El primero, que va desde la apertura del fraccionamiento en 1985 hasta el fin del siglo XX; el segundo, del 2001 al 2008, cuando sucede la crisis inmobiliaria de los sub-prime en Estados Unidos de América; mientras que la tercera oleada considera una década (2009-19). Es de notar en la tabla 3, la dinámica de los conjuntos seleccionados.

Tabla 3. Desarrollos inmobiliarios recientes en Marina Vallarta

\begin{tabular}{|c|c|c|c|c|c|c|c|}
\hline Desarrollo & $\begin{array}{l}\text { Superficie } \\
\text { terreno } \mathrm{m}^{2}\end{array}$ & $\begin{array}{c}\text { Superficie } \\
{\text { construible } \mathbf{m}^{2}} \\
\text { normativa* }^{*}\end{array}$ & $\begin{array}{l}\text { Superficie } \\
\text { construida }\end{array}$ & $\begin{array}{l}\text { Unidades } \\
\text { privativas }\end{array}$ & $\begin{array}{c}\text { Unidades } \\
\text { privativas } \\
\text { normativa }^{*}\end{array}$ & $\begin{array}{c}\text { Altura } \\
\text { (niveles) }\end{array}$ & $\begin{array}{c}\text { Altura } \\
\text { normativa } \\
\text { (niveles) }^{*}\end{array}$ \\
\hline Puesta del Sol & $27,985.21$ & $33,582.26$ & $44,146.26$ & 160 & 215 & 5 & 5 \\
\hline Las Palmas & $11,962.25$ & $14,354.71$ & $19,113.24$ & 57 & 92 & 5 & 5 \\
\hline Las Palmas 2 & $10,542.28$ & $12,650.73$ & $15,447.58$ & 66 & 81 & 5 & 5 \\
\hline $\begin{array}{l}\text { Bay View } \\
\text { Grand }\end{array}$ & $73,873.61$ & $73,873.61$ & $116,713.36$ & 483 & 568 & 8 & 14 \\
\hline Caracoles & $40,277.70$ & $40,277.70$ & $35,893.75$ & 91 & 310 & 8 & 14 \\
\hline Shangri Lá & $42,792.48$ & $42,792.48$ & $64,480.30$ & 190 & 329 & 8 & 14 \\
\hline V Marina & $6,725.20$ & $11,769.10$ & $18,422.82$ & 120 & 53 & 8 & 9 \\
\hline Náutico & 910 & $1,137.50$ & $7,150.00$ & 96 & 7 & 5 & 12 \\
\hline $\begin{array}{c}\text { Marina } \\
\text { Residencies }\end{array}$ & $8,084.28$ & $8,084.28$ & $14,130.06$ & 140 & 67 & 5 & 7 \\
\hline Total & $223,153.02$ & $238,522.36$ & $335,497.37$ & 1,403 & 1,903 & No aplica & No aplica \\
\hline
\end{tabular}

Fuente: Plan Maestro de Marina Vallarta, Plan de Desarrollo Urbano (1997) y Plan Parcial de Desarrollo Urbano del sub-distrito 5-A Marina Vallarta (2012) y elaboración propia.

El análisis muestra diferencias en la dotación de unidades de vivienda turística, el volumen construido y la superficie de los predios en los tres periodos ${ }^{13}$. Entre 1985 y 2000, se respetan las normas de control urbanísticas en todos los rubros menos en la superficie construida total; de 388 unidades posibles, se acreditan 283. Para el segundo periodo (2001-2008), acomete la masiva urbanización de complejos extra-hoteleros; de 1,207 departamentos posibles de acuerdo a la norma, se apertura solamente 764. En la última década, el tamaño de los lotes es significativamente menor, pero se acrecientan las implicaciones en todos los rubros, sobre todo en la cantidad de departamentos, construyéndose 356 cuando eran posibles solo 127.

La superficie total construida se excede en casi cien mil metros cuadrados; de haberse capturado la plusvalía en los nueve ejemplos mostrados (y considerando la tasa del año 2019), más de nueve millones de dólares estadounidenses ingresarían a las finanzas públicas de Puerto Vallarta, que pudieron incidir en la rehabilitación de infraestructura básica. Con ello, se asiste a procesos sostenidos de extracción territorial asociada a la actividad recreativa.

La relación entre los vecinos y empresarios de Marina Vallarta con el gobierno local entró en una etapa ríspida al darse a conocer la actualización del Plan Parcial de Desarrollo Urbano (PPDU) de la colonia en 2017, que sugería un crecimiento exponencial de departamentos turísticos. Las inquietudes insistían en que la sobrecarga edificada impactaría las buenas

\footnotetext{
12 En este caso, referido al Plan Parcial de Desarrollo Urbano del sub-distrito 5-A Marina Vallarta, aprobado en 2012 y que establecía las normas de control a escala más detallada. Curiosamente, dicho Plan Parcial fue modificado en septiembre del 2018 para incrementar los coeficientes urbanizables para la vivienda vertical turística, así como establecer un corredor de usos mixtos, decisiones que van en contra de las peticiones formuladas por los vecinos ante la autoridad municipal en el foro de consulta previo realizado en marzo del 2018.

${ }^{13}$ Para efectos de este trabajo, solamente se consideraron 3 conjuntos emblemáticos por periodo, seleccionados por su condición emblemática y por razones de pertinencia en el manejo de la información.
} 


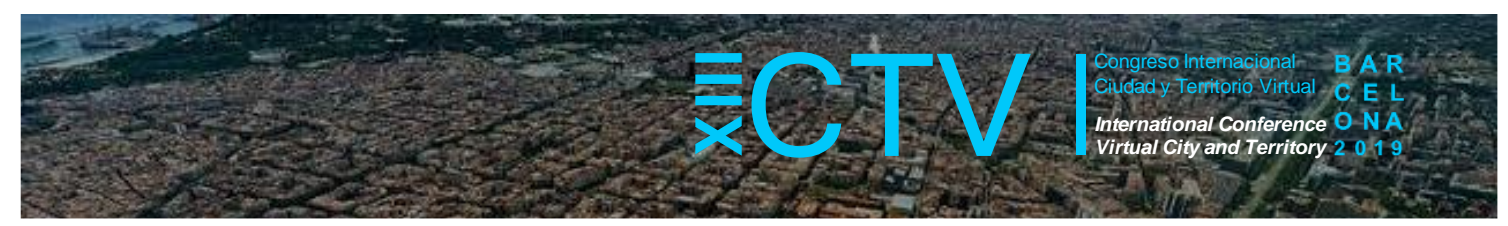

condiciones del fraccionamiento en su conjunto (Arenas, 2017). En noviembre de ese año, el Consejo Coordinador Empresarial convocó a una reunión con representantes del Ayuntamiento, cúpulas empresariales, organismos públicos y privados, investigadores y vecinos con el objetivo de atender la masiva edificación en Marina Vallarta. En el encuentro se expresó la inconformidad por la masiva edificación imperante (ejemplificada en más de 24 desarrollos en proceso), muchos de los cuales no cumplían con la reglamentación urbanística, así como la preocupación por los efectos que tendría la masificación. El alcalde vallartense indicó que el proceso estaba apegado a reglamentos y ofreció convocar a mesas de trabajo para atender la problemática (Mora, 2017), compromiso que no sucedió. Meses después, ante el incumplimiento a los acuerdos y particularmente tras la modificación al PPDU de la demarcación, en septiembre del 2018, la Asociación de Residentes de Marina Vallarta realizó una manifestación bloqueando la principal avenida de la ciudad, exigiendo que, "No se realizasen cambios de uso de suelo de habitacional a mixto o comercial, mantener las alturas de nuevos edificios en la zona a 8 niveles máximo, y que se siga respetando la declaratoria como Polígono de Desarrollo Controlado ${ }^{14}$ del fraccionamiento" (Garda, 2018).

A las protestas, se sumaron vecinos de otras colonias, que están experimentando procesos de densificación, obtenidas mediante la construcción de desarrollos inmobiliarios verticales. Los funcionarios municipales alegan que siguen los planteamientos de la ciudad compacta propuestos por organismos internacionales como ONU-HÁBITAT ${ }^{15}$ o nacionales como la Secretaría de Desarrollo Agrario, Territorial y Urbano (SEDATU). Pero el reclamo ciudadano apunta hacia la gestión del suelo urbano, donde la densificación considere mecanismos compensatorios para aminorar las cargas ejercidas por la urbanización. Dentro de las sugerencias destaca la captura de plusvalía, generación de espacio público y adaptación a la infraestructura básica como un medio para balancear la voracidad de la expansión inmobiliaria extractiva asociada a la habilitación de vivienda para hospedaje colaborativo.

\section{Planeación urbana en México y Puerto Vallarta}

México fue pionero en la práctica de planeación urbana en América Latina al consagrarse en la Constitución Política de 1917 la intervención del Estado en los derechos de propiedad y de regulación del suelo urbano (Azuela, 2013; Garza, 2003). En 1976 se promulgó la Ley General de Asentamientos Humanos ${ }^{16}$ (LGAH), con el objetivo de normar el proceso de expansión y establecer la concurrencia de la Federación, estados y municipios para fijar las normas para la fundación, conservación, mejoramiento y crecimiento de los centros de población (Azuela, 2016). De esta manera, se configuró el marco normativo e instrumental para atender el crecimiento acelerado urbanístico mexicano, en una dinámica que parecía fuera de control, en particular en la zona metropolitana del Valle de México (ZMVM).

\footnotetext{
${ }^{14}$ La figura de Polígono de Desarrollo Controlado está contemplada en el artículo 5o, inciso LIV del Código Urbano para el Estado de Jalisco y se define como la "superficie delimitada del suelo que se determina en un plan parcial de desarrollo urbano mediante declaratoria y aprobación del ayuntamiento correspondiente a solicitud de una asociación de vecinos legalmente constituida, para llevar a cabo acciones determinadas mediante un convenio celebrado entre el propio ayuntamiento y la asociación reconocida en el área de aplicación". Es un mecanismo de coadyuvancia y coordinación entre el gobierno estatal, municipal y los vecinos, figura que existía en el Plan Parcial de Desarrollo Urbano del sub-distrito 5aㅡ Marina Vallarta, aprobado en 2012.

${ }_{15}$ La Nueva Agenda Urbana propuesta por ONU-HÁBITAT (2016), busca en el objetivo 3.5 lograr una forma espacial urbana compacta, conectada, integrada, segura e inclusiva, mediante componentes claves como la prevención de la expansión urbana.

${ }^{16} \mathrm{La}$ aprobación de la LGAH formaba parte de los compromisos asumidos por México tras la celebración en Vancouver de la primera reunión global sobre ciudades denominada Hábitat $I$, la cual fue convocada por la Organización de las Naciones Unidas (ONU) en ese mismo año.
} 


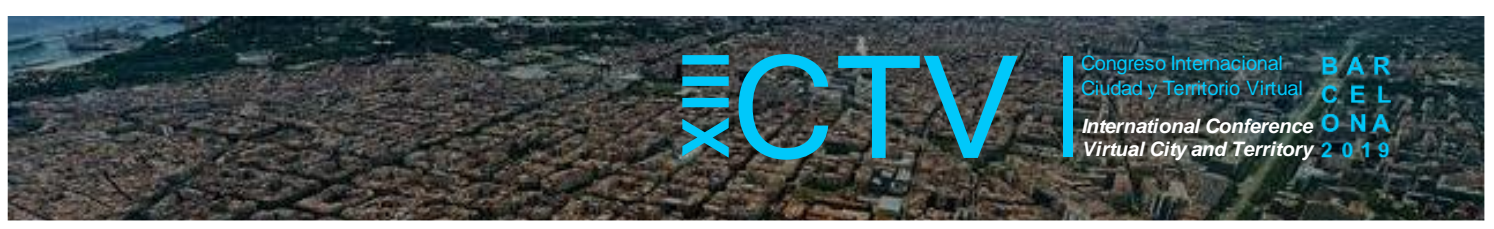

En las ciudades turísticas de litoral, los esfuerzos de planeación se remontan a la década de 1930 con la formulación del primer Plano Regulador de Acapulco (Valenzuela, 2014). A partir de entonces, comenzaron a gestarse los instrumentos de ordenamiento para preparar a los territorios recreativos ante los embates de un crecimiento intenso y sostenido. En 2016, fue actualizada la Ley General de Asentamientos Humanos, Ordenamiento Territorial y Desarrollo Urbano (LGAHOTyDU) con el objetivo de homologar el marco normativo, incorporando la dimensión territorial y urbana. A pesar los logros alcanzados ${ }^{17}$ se dejó pasar la oportunidad de re-estructurar la arquitectura institucional de la planeación urbana nacional, manteniendo el método de planeación raciona ${ }^{18}{ }^{8}$ de amplia tradición en la práctica mexicana (Kunz, 2017).

En México, la administración del desarrollo urbano corresponde al Ayuntamiento (gobierno local), de quien penden muchas atribuciones y competencias, determinadas en el artículo 115 constitucional (SEDESOL y ONU HÁBITAT, 2011). El objetivo inicial coincidía en el ánimo de descentralización administrativa y fortalecimiento a la autonomía municipal. Pero los esfuerzos institucionales y normativos en materia de desarrollo urbano nacional, topa con debilidades institucionales donde el Estado (y sus operarios) relega el carácter político del ejercicio de planear dejando de aplicar el vasto instrumental de facultades y prerrogativas de que dispone (Garrocho, 2015). En contrapartida, establecen acuerdos informales con los agentes económicos privados (Holmes, 2019) quienes capturan para su beneficio el valor generado por el propio proceso de urbanización (García Canclini, 2016). Ello se materializa con mayor virulencia en las ciudades turísticas de playa donde la modificación discrecional de los planes urbanos ha sido la punta de lanza para amasar grandes fortunas (Speakman, 2018).

\subsection{Iniciativas pioneras de la planeación urbana en Puerto Vallarta}

Tres iniciativas impulsadas por el gobierno federal y de Jalisco constituyen el origen de la planeación en Puerto Vallarta: la primera, fue el Programa de Progreso Marítimo (también conocido como la Marcha al Mar) formulado en la administración del presidente Adolfo Ruíz Cortines en 1953 (Gómez, 2008).; la segunda, impulsada en ese mismo año por la administración jalisciense con la Comisión de Planeación de la Costa de Jalisco ${ }^{19}$ creada con el objetivo de ampliar las oportunidades en el litoral jalisciense (Scartascini, 2011); la tercera fue la expropiación de 1,026 hectáreas al ejido Puerto Vallarta, instrumentándose en 1973 el Fideicomiso Traslativo respectivo para asegurar la tenencia de la tierra y consolidar el crecimiento urbano, turístico y económico. Estas determinaciones fueron formuladas como parte de las políticas de desarrollo turístico del Estado mexicano durante la posguerra para captar divisas, crear fuentes de empleo y fomentar el desarrollo regional en el país (Brenner, 2007).

\footnotetext{
${ }^{17}$ Las principales aportaciones ocurrieron en materia de financiamiento, búsqueda de equidad y políticas públicas base territorial para México, como menciona Kunz (2017).

${ }^{18} \mathrm{La}$ planeación racional constituye el paradigma clásico y pionero dentro de la práctica urbanística moderna; las bases epistemológicas se ubican en el positivismo científico, planteando que la razón es el medio de entender la realidad de manera concreta y objetiva, mientras que la ciencia es el método válido para generar conocimiento donde el espacio es comprendido desde un enfoque físico absoluto euclidiano. El rol del planificador es la de un científico aplicado y un constructor de decisiones que intenta determinar el uso más eficiente, con el menor impacto y reduciendo la fricción en los procesos de crecimiento de la ciudad. La principal herramienta consiste en la zonificación, por medio de la cual se separan las funciones y actividades por medio de la asignación de usos de suelo que se adaptan a las características del medio natural, construido y socio-económico en el espacio urbano. (Fernández, 2014; Peña, 2016).

${ }^{19}$ De acuerdo a Munguía (1997), las funciones de la Comisión fueron planear la economía, formular los estudios y promover obras de interés colectivo, intentando solucionar tres problemáticas: 1) la desigualdad económica y poblacional en Jalisco; 2) aprovechar los recursos naturales de la costa; y, 3) abastecer a las áreas de mayor concentración demográfica y económica como Guadalajara.
} 


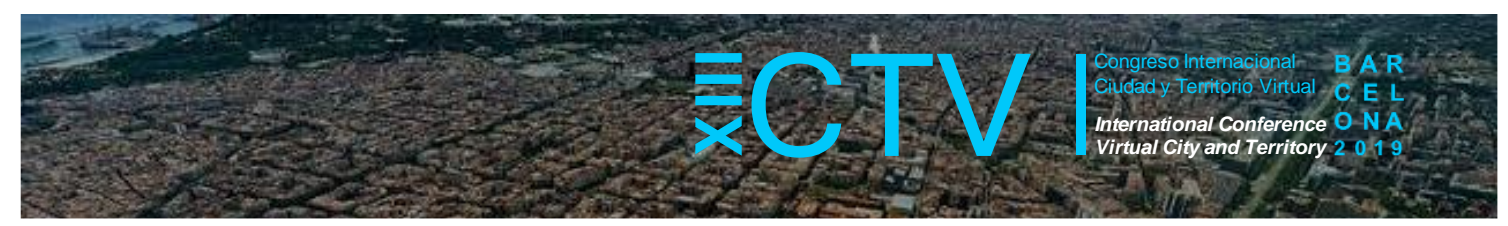

El fortalecimiento y posterior adopción de la actividad turística como la principal fuente de ingresos para Puerto Vallarta alentó un rápido crecimiento poblacional y urbano; con ello, fue necesario implementar mecanismos para potenciar las bondades y reducir los impactos negativos de la expansión territorial (Baños, 2010). De esta manera, en 1975 se aprobó el Plan General Urbano ${ }^{20}$, elaborado por la Junta General de Planeación y Urbanización de Jalisco, considerando la importancia de la localidad para la economía de la entidad y anotando los retos por enfrentar, como el acelerado crecimiento demográfico, la expansión urbana y la presencia de una importante población flotante (Casillas, 1982; JGPUEJ, 1975).

\subsection{El Plan de Desarrollo Urbano de 1997}

En el año 1997 se aprobó el Plan de Desarrollo Urbano (PDU) ${ }^{21}$ de Puerto Vallarta, estableciéndose las medidas aplicables a la acción urbanística, a fin de regular y controlar las actividades de conservación, mejoramiento y crecimiento urbano. EI PDU prevaleció por más de quince años, contribuyendo en las políticas de ordenamiento en el territorio vallartense, sin embargo, sus metas fueron rebasadas por la velocidad de la expansión, así como la combinación de intereses en torno a la especulación inmobiliaria, debilidad institucional, corrupción gubernamental y escasa participación ciudadana (Baños, 2015). Tampoco se logró innovar la práctica de planeación urbana limitándose a aplicar el modelo racional que tiene como herramienta la determinación de usos de suelo (zonificación) en aras de conducir la gestión desde la visión técnica de los funcionarios municipales en turno. Ello dificultó la promoción de un desarrollo urbano con criterios de sustentabilidad, a pesar de que se realizaron diversos intentos ${ }^{22}$ por actualizar los instrumentos de ordenamiento territorial y planeación urbana en varias administraciones municipales (Verduzco, 2013).

\subsection{La planeación urbana por distritos, 2011 a la fecha}

La falta de consensos para actualizar los instrumentos urbanísticos y la necesidad de mejorar la gestión alentó que en el año 2011, el Ayuntamiento de Puerto Vallarta aprobara la división en diez distritos ${ }^{23}$ dentro del Límite de Centro de Población (LCP) ${ }^{24}$. La división por distritos impulsó la formulación de Planes Parciales de Desarrollo Urbano (PPDU), que son instrumentos de ordenamiento más detallados para ajustarlos a las exigencias de cada zona. Los esfuerzos se tradujeron en la aprobación de diez PPDU en 6 años, lo cual constituyó un avance cuantitativo en la práctica urbanística de Puerto Vallarta.

\footnotetext{
${ }^{20}$ El Plan General Urbano constituye el primer instrumento de planeación urbana en Puerto Vallarta y sus alcances fueros modestos dado el tamaño de la población y el grado de conocimientos técnicos sobre urbanística. Pero aportó abundante información sobre el medio natural, edificado y socioeconómico de la época, incluyendo una amplia cartografía temática (Casillas, 1982).

${ }^{21}$ EI PDU cuenta con 8 capítulos; ahí se determinan el conjunto de políticas, lineamientos, estrategias, reglas técnicas y disposiciones para promover el desarrollo armónico de un centro de población.

22 Los esfuerzos de actualización del PDU acontecieron en los años 2003, 2006 y 2009, coincidiendo con el primer año del ejercicio de gobierno municipal. Baños (2015) sostiene que no se lograron conciliar los intereses de los actores en torno al territorio y el urbanismo, dejándose pasar la oportunidad de mejorar la práctica de la planeación urbana local. Y la formulación de los Planes Parciales de Desarrollo Urbano tampoco parecen haber incidido positivamente en la gestión urbana vallartense.

${ }^{23}$ La metodología para delimitar los distritos urbanos se adoptó considerando las características del medio natural, urbano y socio-económico, así como de la información estadística de las Áreas Geoestadísticas Básicas (AGEB) del Instituto Nacional de Geografía y Estadística (INEGl); a pesar del esfuerzo por homologar y equilibrar las porciones territoriales, persistieron algunos desajustes como la distribución poblacional en ciertas demarcaciones.

${ }^{24}$ El Límite de Centro de Población (LCP) comprende las áreas dentro de las que el Ayuntamiento de Puerto Vallarta está obligado a generar y aplicar instrumentos de planeación urbana; en el caso local abarca una superficie aproximada de once mil hectáreas.
} 


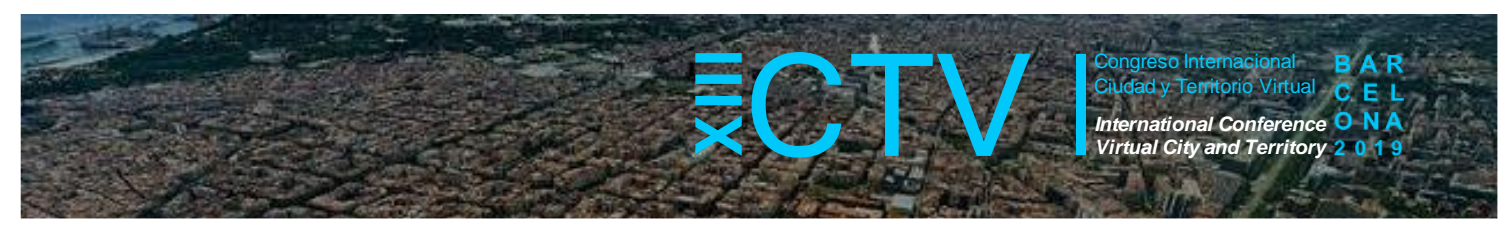

Los PDU aprobados entre 2012 y 2018 fueron en los distritos 1 (Río Ameca), 2 (Ixtapa), 3 (Mojoneras), 4 (El Pitillal), 5A (Marina Vallarta), 5B (Estero El Salado), 6 (Zona Hotelera Norte), 9 (Amapas-Conchas Chinas), 10 (Zona Sur) y Arroyo El Quelitán, éste último fuera del LCP. En un proceso posterior se realizó el procedimiento para el PPDU del distrito 7 (IndependenciaLópez Mateos) pero no alcanzó validez jurídica por no haber sido publicado en la Gaceta municipal. Finalmente, el distrito 8 (Centro Histórico-5 de diciembre-Emiliano Zapata) no dispone de ordenamiento detallado a pesar de su importancia simbólica, turística y económica, al alberga al Centro Histórico y la Zona Romántica, ésta última una de las de mayor auge inmobiliario asociado al hospedaje colaborativo, como se detallará más adelante. Pese a disponer de una sólida batería de PPDU en Puerto Vallarta, en la práctica no se han respetado los postulados de la planeación urbana ni se contiene a la marea especulativa del sector inmobiliario, en particular en la franja turística, que es donde crece la oferta de hospedaje colaborativo (Baños, 2015).

\subsection{La discrecionalidad en la toma de decisiones urbanas}

Un recurso muy socorrido y quizá la mayor debilidad de la arquitectura institucional de la planeación local, ha sido modificar discrecionalmente las reglas urbanísticas invocando que los planes no corresponden con las condiciones del contexto inmediato, en particular en las áreas urbanizadas. Adicionalmente, se refiere a la política de densificación urbana propuesta por el gobierno federal en la administración 2012-201825. Aprovechando esta facultad discrecional, los promotores pueden solicitar a la autoridad municipal la alteración de las normas de control de la edificación mediante la presentación de un Análisis Técnico Justificativo (ATJ) basados en una alevosa interpretación del artículo $35^{26}$ del Reglamento de Zonificación para el municipio de Puerto Vallarta. Ello significó:

1.- Un incremento de la masa construida. Como se advierte en la tabla 1, en la Zona Romántica se autorizó la edificación de más del trescientos por ciento de lo establecido en la norma. Así, la superficie de desplante ${ }^{27}$ aumenta, como también sucede con el total edificable ${ }^{28}$. Una paradoja es que, tras revisar los catorce expedientes señalados, se anotó que la autoridad municipal concedió más del área construida resultante de los ATJ presentados. Similar situación se presenta en Marina Vallarta, de acuerdo a los valores mostrados en la tabla 2.

2.- Dado que los predios tienen superficies reducidas, se incrementa la densidad y altura, modificando la escala, el paisaje tradicional y el carácter de barrio. Esto tiene implicaciones en la gestión del destino, toda vez que uno de los elementos diferenciadores de la oferta turística de Puerto Vallarta estaba asociada a su imagen de población de baja

\footnotetext{
25 Uno de los seis objetivos establecidos en el Programa Nacional de Desarrollo Urbano 2012-2018 establecido por el gobierno federal encabezado por Enrique Peña Nieto era controlar la expansión de las manchas urbanas y consolidar las ciudades para mejorar la calidad de vida de los habitantes dado que, en México, se imponía una expansión desordenada debido a un modelo ineficiente de desarrollo urbano. Si bien la meta es adecuada y pertinente a la realidad nacional, su aplicación ha servido para validar dinámicas extractivas en el territorio por parte del sector inmobiliario, en complicidad con la autoridad respectiva.

${ }^{26}$ El mencionado artículo señala que "en las áreas urbanizadas para la aplicación de las normas de control de la edificación se observarán las siguientes consideraciones: i) Las normas de control de la edificación referentes a dimensiones, coeficientes, alturas, estacionamiento y restricciones que se establezcan para las zonas en los planes parciales de desarrollo urbano, serán tomando en cuenta las características actuales de su área de aplicación, y en caso de no existir estos, la autoridad municipal dictaminara considerando el contexto inmediato". La cursiva es de los autores.

${ }^{27}$ Identificado en la legislación local como el Coeficiente de Ocupación de Suelo (COS).

${ }^{28}$ Identificado en la legislación local como el Coeficiente de Ocupación de Suelo (COS).
} 


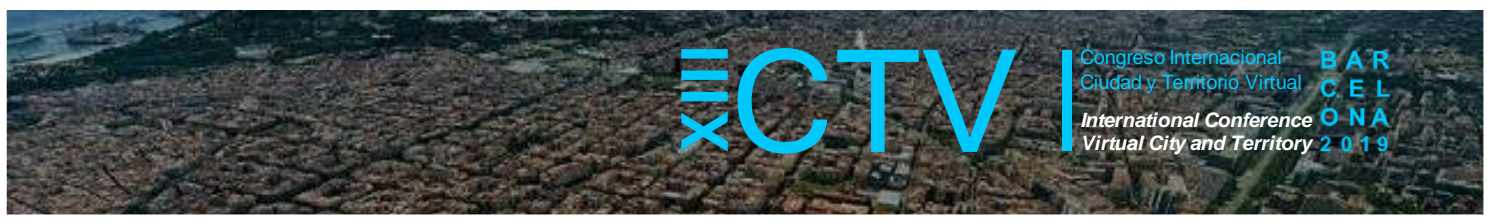

densidad y escala, relacionado con elementos de autenticidad arquitectónica mexicana, aspectos que se han diluido con la masificación en los edificios.

3.- También se alteraron la cantidad de unidades privativas, referidas al número de viviendas que puede soportar un terreno. Tanto en la Zona Romántica como en Marina Vallarta, se obtienen incrementos de hasta siete veces de lo permitido. Aquí radica el mayor truco de los acuerdos informales y la discrecionalidad del urbanismo vallartense reciente: generar mayores unidades para su comercialización, donde no es lo mismo vender un bien que hacerlo siete veces.

4.- Oportunidades perdidas, ya que las autorizaciones municipales no alentaron la captura de la plusvalía que fue obsequiada a los promotores privados sin beneficio para la comunidad. Es decir, el Ayuntamiento dejó pasar la oportunidad para que dichos recursos animaran la equidad socio-espacial y contuvieran los impactos generados por la masiva urbanización, expresada en tensiones a las redes de infraestructura básica (agua, alcantarillado, luz), dotación de espacios públicos de calidad y mejoramiento de la movilidad, particularmente mediante mejoras a los sistemas de transporte colectivo.

5.- Sobrecarga a los sistemas de infraestructura urbana, en particular a la red de agua potable y alcantarillado. De acuerdo al organismo operador del agua (SEAPAL), se requiere de una inversión superior a los siete millones de dólares estadounidenses para rehabilitar el sistema de drenaje en la Zona Romántica, cifra que pudo ser financiada (al menos parcialmente) por los desarrollos inmobiliarios construidos en el barrio. Pero ello no sucedió, con lo cual el costo de rehabilitación será pagado con dinero público.

Para hacer frente a estas prácticas alevosas, diversas asociaciones de vecinos ${ }^{29}$, en particular en la franja turística, han intentado colaborar estableciendo una gestión urbanística compartida. La acción más significativa consistió en la aprobación del Plan Parcial de Desarrollo Urbano del Distrito 9, que tuvo como objetivo equilibrar del crecimiento de la franja turística.

Vale subrayar que otra debilidad en el ordenamiento urbano de Jalisco y Puerto Vallarta radica en la naturaleza de los planes, basados en la zonificación como la herramienta empleada para conducir el proceso de expansión. Si bien este método de planeación funcionó entre la Revolución Industrial y la segunda mitad del siglo XX (García Vázquez, 2016), en los tiempos actuales muestra debilidades para absorber y regular las profundas y veloces transformaciones en el espacio urbano.

O quizá la ineficaz aplicación de los instrumentos existentes puede deberse a la acción de intereses particulares asociados al capital inmobiliario, así como a la debilidad del talento humano dentro de la administración pública para innovar la práctica urbanística. Así, la arquitectura institucional de la planeación urbana en Puerto Vallarta parece alejarse de la aspiración de un desarrollo sustentable que esté a la altura de los bienes territoriales y naturales con que cuenta el territorio local.

\section{Consideraciones finales}

Los progresos tecnológicos abren nuevos horizontes de negocios transformando los procesos económicos a escala planetaria. En el sector turístico, han facilitado la prestación del servicio de hospedaje en una modalidad colaborativa, inicialmente pero que ha tornado a las formas antiguas de capitalismo extractivo (Brossat, 2018).

29 Destacando los esfuerzos de la Asociación de Residentes de Marina Vallarta, la Asociación de Residentes de Amapas, así como los de Conchas Chinas, integrados con un fuerte componente de habitantes estadounidenses. 


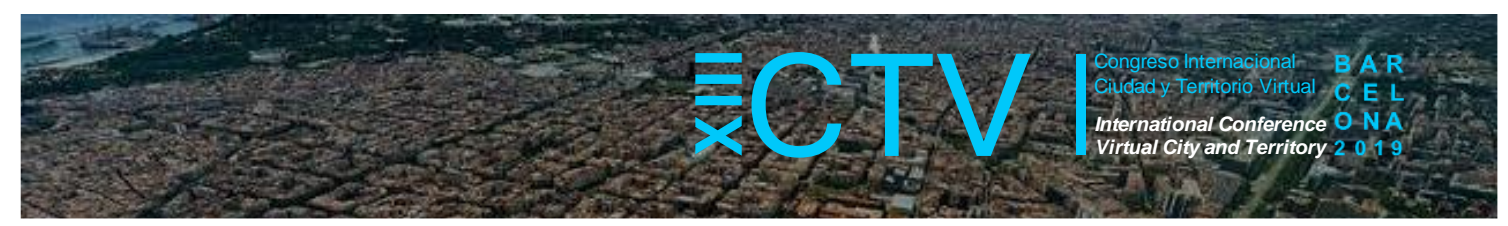

Ello impulsa al sector inmobiliario en destinos recreativos materializados en viviendas de segunda residencia que se ofertan masivamente y entran en competencia con la oferta de hospedaje hotelero. A pesar de los esfuerzos desplegados por los entes gubernamentales para conciliar los intereses de los agentes involucrados y enfrentar la problemática, los logros son insuficientes. Lo anterior se complica en países como México cuya arquitectura institucional se basa en la extracción de los bienes comunes para favorecer intereses privados (Acemoglu y Robinson, 2012). Sin embargo, es posible incorporar medidas de gestión de base territorial articulada con instrumentos de planeación urbana; para el caso de Puerto Vallarta, México, se sugieren tres acciones.

La primera es decretar Polígonos de Actuación Prioritaria (PAP) en las zonas atractivas para el desarrollo inmobiliario y formular un diagnóstico preciso de las condiciones de infraestructura, movilidad y equipamientos requeridos para soportar la expansión. Ello permitirá disponer de información que redunde en instrumentos flexibles y adecuados para absorber el desarrollo futuro y asegurar que se disponga de las condiciones para el crecimiento equilibrado. Como resultado, el parque de vivienda turística para el hospedaje colaborativo deberá contar con óptimas condiciones de habitabilidad.

La segunda, considera que la plusvalía resultante de la flexibilización en los derechos de desarrollo urbanísticos sea incorporada por el Ayuntamiento mediante mecanismos fiscales de capturar para financiar las obras de rehabilitación asociadas a la expansión urbana. Ello es particularmente sensible en el caso mexicano, dado que la Constitución otorga muchas obligaciones y facultades a los gobiernos locales pero el esquema fiscal es inequitativo, al tener que redistribuirse los magros ingresos locales en una escala nacional. De esta manera, los municipios prósperos resultan financiando a los de bajos ingresos, pero tampoco destacan medidas creativas e innovadoras para ampliar los recursos que los municipios requieren para enfrentar sus múltiples tareas.

Finalmente, es pertinente activar un Mecanismo de Integración Residencial para equilibrar los desajustes generados por un modelo de desarrollo altamente depredador que aprovecha los recursos territoriales para maximizar las ganancias especulativas pero que evita comprometerse en mejorar las condiciones de vida de la comunidad. El objetivo es reducir la brecha entre los residentes de altos ingresos (la mayoría de ellos, extranjeros) y los pobladores locales toda vez que la franja turística aloja barrios con todos los servicios y amenidades al tiempo que otras unidades habitacionales carecen de un hábitat adecuado. Dentro de las acciones a emprender destacan: a) cuotas de vivienda social en la franja turística, donde un porcentaje de la oferta sea adquirida por residentes para su uso sin poder obtener beneficios como valor de cambio; b) promover mixtura social, etaria y nacional entre residentes; disponibilidad de espacios públicos de calidad y con acceso universal. Si el Estado, en conjunto con la sociedad no actúa de manera decidida para acceder a una ciudad para todos, continuará aumentando la brecha entre grupos con resultados que pueden generar implicaciones negativas para el colectivo social.

Contribuciones de los autores: José Alfonso Baños Francia contribuyó con la narrativa de la vivienda turística así como el análisis de los instrumentos de planeación urbana en México y Puerto Vallarta. María de los Ángeles Huízar Sánchez se enfocó en la economía y hospedaje colaborativo, así como en la discusión turística local. Jorge Luis López Ramos colaboró con 


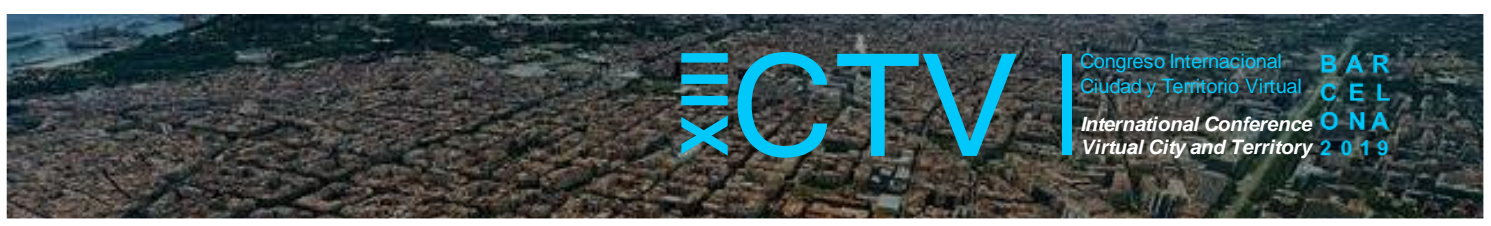

fundamentos legales del desarrollo turístico y urbano vallartense, así como el análisis de las formas de hospedaje (hotelero, tiempo compartido y colaborativo).

Conflicto de Intereses: Los autores declaran que no hay conflicto de intereses.

\section{Bibliografía}

Acemoglu, D. y Robinson, J. (2012). Porqué fracasan los países. Los orígenes del poder, la prosperidad y la pobreza. Ciudad de México, México: Crítica.

A21mx. (30 de noviembre de 2017). Airbnb crece 165\% en México y va por turistas nacionales. Diario en línea A21mx. Recuperado de https://a21.com.mx/innovación/2017/11/30/airbnb-crece165-en-mexico-y-va-por-turistas-nacionales

Alonso, M. y Miranda, A. (2017). La empresa colaborativa. La nueva revolución económica. Madrid, España: Pearson.

Airdna. (2018). Airbnb data \& insights to suceed in the sharing economy. Inglaterra. Recuperado de https://www.airdana.co

Arenas, S. (31 de julio 2018). Preocupa a residentes de Marina Vallarta edificación con altura excedente. Observatoriobahía.com.mx. Recuperado de http://observatoriobahia.mx/preocupaa-residentes-marina-vallarta-edificacion-altura-excedente/

Azuela, A. (2016). Introducción. Una especie de neorrealismo jurídico. En A. Azuela (coord.), La ciudad y sus reglas. Sobre la huella del derecho en el orden urbano. (pp. 9-42). Ciudad de México, México: Universidad Nacional Autónoma de México (UNAM) y Procuraduría Ambiental y del Ordenamiento Territorial de la Ciudad de México (PAOT).

Azuela, A. (2013). El ordenamiento territorial en la legislación mexicana. En: M.T. Sánchez, G. Bocco y J.M. Casado (coords.) La política de ordenamiento territorial en México: de la teoría a la práctica. (pp. 47-78). Ciudad de México, México: Universidad Nacional Autónoma de México, UNAM.

Baños, A. (2018). Arquitectura y urbanismo en Puerto Vallarta en el centenario como municipio. En H. Pérez y A. Baños (coords.), Puerto Vallarta, 2018. Temas del Centenario. (pp. 99-111). Guadalajara, México: Colegio de Jalisco y Universidad de Guadalajara.

Baños, A. (2017). Segregación residencial en el espacio turístico de Puerto Vallarta. Guadalajara, México: Universidad de Guadalajara.

Baños, A. (2015). Planeación y políticas urbanas en Puerto Vallarta. Estudios Jaliscienses, 101, 30-41.

Baños, A. (2010). Arquitectura y urbanismo en Puerto Vallarta. Una mirada a la construcción de una ciudad turística de litoral. Puerto Vallarta, México: Instituto Tecnológico Superior de Puerto Vallarta.

Botsman, R. y Rogers, R. (2010). What's mine is yours. The rise of collaborative consumption. Nueva York, Estados Unidos de América: Harper Collins. 


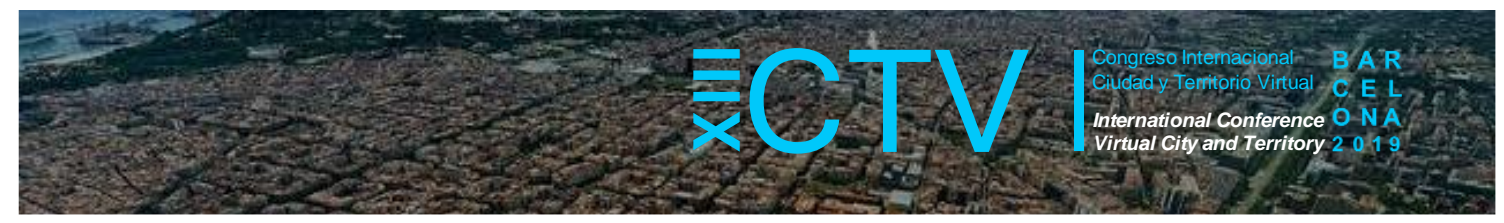

Brenner, L. (2007). La política turística mexicana y su impacto en el desarrollo nacional y urbano-regional. En B. L. Cámara (coord.). Urbanización y turismo. (pp. 13-38). Chetumal, México: Universidad de Quintana Roo y Pomares.

Brossat, I. (2018). Airbnb, la ciudad uberizada. Pamplona, España: Katakrak.

Cañigueral, A. (2014). Vivir mejor con menos. Descubre las ventajas de la nueva economía colaborativa. Barcelona, España: Conecta.

Casillas, G. (octubre, 1982). Plan General Urbano de Puerto Vallarta. Trabajo presentado en la Reunión de exposición sobre Urbanismo y Vivienda del municipio de Puerto Vallarta, Puerto Vallarta, México.

César, A. y Arnaiz, S. (2006). Territorio y Turismo. Nuevas dimensiones y acciones. Guadalajara, México: Universidad de Guadalajara.

Fernández de Córdoba, M.B. (2014). Introducción a la teoría de la planificación territorial. Sevilla, España: Universidad de Sevilla.

García Canclini, N. (2016). ¿El soborno es el nuevo contrato social? En Habitar la ciudad. (pp. 77-84). Ciudad de México, México: Arquine.

García Vázquez, C. (2016). Teorías e historias de la ciudad contemporánea. Barcelona, España: Gustavo Gili.

García, J.G. (21 de mayo 2019). "Dinkis", el sector que gasta más que una familia cuando viene a Puerto Vallarta. AZ Noticias. Recuperado de: https://aznoticias.mx/index.php/puerto-vallartamovil/32365 di...-que-gasta-mas-que-una-familia-cuando-viene-a-puerto-vallarta/

Garda, J.C. (22 septiembre de 2018). Manifestación y bloqueos en Marina Vallarta. Vallarta Opina. Recuperado de: http://vallartaopina.net/2018/09/22/local/ciudad/manifestacion-ybloqueo-en-marina-vallarta/

Garrocho, C. (2015). Prólogo. En A. Lindón y C. Mendoza (coords.), La periferia metropolitana: entre la ciudad prometida y un lugar para habitar la Ciudad de México. Ciudad de México, México: Gedisa y UAM.

Garza, G. (2003). La urbanización de México en el siglo XX. Ciudad de México, México: El Colegio de México.

Gómez Encarnación, J.M. (2008). Tres Municipios en la Bahía de Banderas. Población y Economía de un pasado en común. Puerto Vallarta, México: Planet.

Harari, Y.N. (2014). De animales a dioses. Breve historia de la humanidad. Ciudad de México, México: Penguin Random House Grupo Editorial.

Kunz, I. (2017). Planeación metropolitana en búsqueda de la integralidad. En I. Kunz (comp.), Planeación metropolitana. En búsqueda de la integralidad. (pp. 15-56). Ciudad de México, México: Siglo XXI.

Hiernaux, D. (2007). La promoción inmobiliaria y el turismo residencial: el caso mexicano. Scripta Nova, volumen IX, num. 194 (05).

Holmes, L. (2019). ¿Qué es la corrupción? Ciudad de México, México: Grano de Sal. 


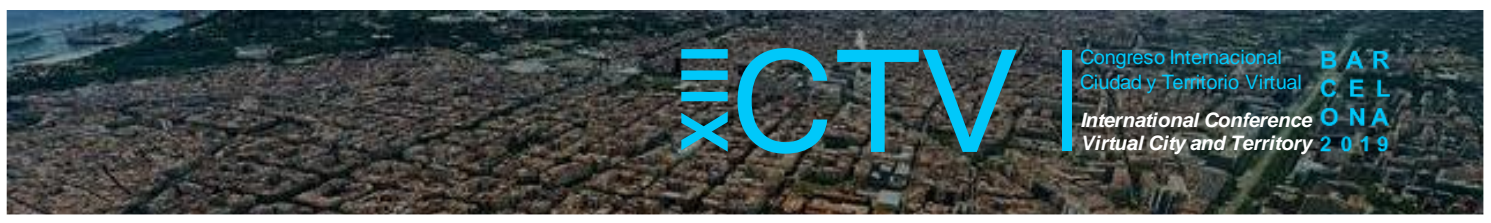

Huízar, M.A. (2018). Desarrollo local y turismo en la región de la Bahía de Banderas. Puerto Vallarta, México: Universidad de Guadalajara.

Huízar, M.A.; Baños, A. y López, J. (2018). El impacto del turismo LGBT en Puerto Vallarta. En S.M. Arnaiz y A.B. Gómez (coords.). El turismo frente a los Objetivos de Desarrollo Sustentable. (pp. 313-330). Puerto Vallarta, México: Universidad de Guadalajara.

Instituto Mexicano para la Competitividad, IMCO. (2017). Airbnb en la Ciudad de México: Extiende los beneficios económicos del turismo y reduce la brecha salarial. Caso de estudio para la capital del país. Ciudad de México, México: IMCO.

JGPUEJ, Junta General de Planeación y Urbanización del Estado de Jalisco. (1975). Plan General Urbano de Puerto Vallarta. Guadalajara, México: Gobierno de Jalisco.

López, J. (2020). Análisis del turismo residencial en Puerto Vallarta: de la segunda residencia al hospedaje colaborativo. Tesis de doctorado en Ciencias para el Desarrollo Sustentable, Universidad de Guadalajara.

Mora, M. (20 de noviembre de 2017). 8 de las 24 construcciones de la Zona Romántica fueron autorizadas en esta administración. Vallarta Independiente. Recuperado de: https://vallartaindependiente.com/2017/11/20/8-las-24-construc...s-la-zona-romantica-fueronautorizadas-en-esta-administracion/

Munguía, C. (1997). Panorama histórico de Puerto Vallarta y de la Bahía de Banderas. Guadalajara, México: Secretaría de Cultura del Gobierno de Jalisco y H. Ayuntamiento de Puerto Vallarta.

Ocaña, MA. (10 de abril de 2017). La Zona Romántica pierde su identidad. Vallarta Opina. Recuperado de http://vallartaopina.net/2017/04/10/s-gente-pv/la-zona-romantica-pierdeidentidad/

ONU Hábitat. (2016). Nueva Agenda Urbana. Nairobi, Kenia: ONU publicaciones.

Peña, S. (2016). Teoría, procesos y prácticas de la planeación urbana y regional. Ciudad Juárez, México: El Colegio de la Frontera Norte.

Pineda, E. (8 de enero de 2020). Supera el aeropuerto 5 millones de turistas. Vallarta Opina, 45.

RCl, Resort Company International. (2017). Resultados 2016. Miami, Estados Unidos de América: RCl. Recuperado de https://www.rci.com

Rifkin, J. (2000). La era del acceso. La revolución de la nueva economía. Madrid, España: Paidós.

Scartascini, G. (2011). Puerto Vallarta. La formación de un destino. Puerto Vallarta, México: Universidad de Guadalajara.

SECTURJAL, Secretaría de Turismo de Jalisco. (2015, 2010, 2005). Anuario estadístico por año. Guadalajara, México: Gobierno de Jalisco.

Secretaría de Desarrollo Social (SEDESOL) y ONU Hábitat. (2011). Estado de las ciudades de México, 2010/2011. Ciudad de México, México: SEDESOL y ONU Hábitat. 


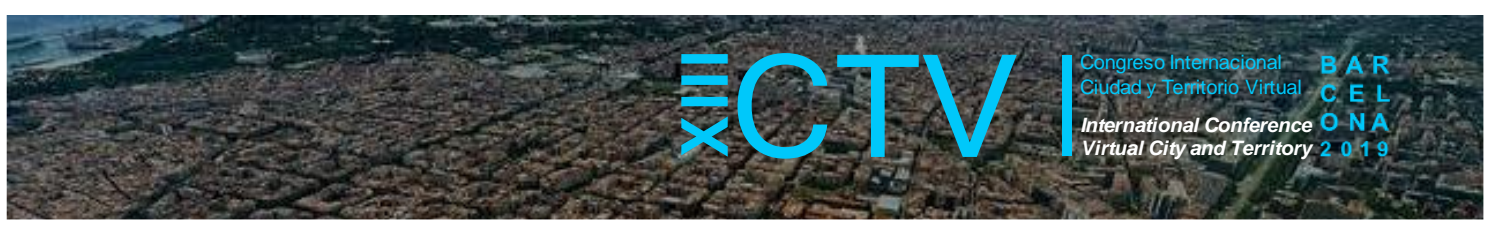

Slee, T. (2017). Lo tuyo es mío. Contra la economía colaborativa. Ciudad de México, México: Taurus.

Soros, G. (2008). El nuevo paradigma de los mercados financieros. Para entender la crisis económica actual. Ciudad de México, México: Taurus.

Speakman, M. K. (2018). El fracaso de los planes de desarrollo turístico de Acapulco: una perspectiva de la teoría de la complejidad. En A. Díaz Garay, I. Solano y M. Speakman. (Eds.), Crisis del turismo tradicional y gestión de nuevos destinos sustentables. (pp. 31-44). Ciudad de México, México: Universidad Autónoma de Guerrero y Porrúa.

Valenzuela, A. (2014). Urbanistas visionarios. La planeación de la Ciudad de México en la primera mitad del siglo XX. Ciudad de México, México: Porrúa.

Verduzco, B. (2013). Una utopía (im)posible. La negociación infinita de planes de desarrollo urbano y prosperidad. Guadalajara, México: Universidad de Guadalajara. 